Universidad Nacional de La Plata.

Facultad de Humanidades y Ciencias de la Educación.

Centro de Historia Argentina y Americana

\title{
¿Quiénes eran los mozos en las regiones mediterráneas? Salarios y movilidad de los mozos en el mercado de trabajo de Mallorca, 1654-1680
}

\author{
Who were the rural servants in Mediterranean regions? Contracts, \\ wages and mobility of servants in the island of Mallorca, 1654-1680
}

\section{Gabriel Jover Avellà *, Joana Maria Pujadas Mora **, Ana Maria Suau Rodríguez *}

* Universitat de Girona, España, ** Centre d'Estudis Demogràfics - Universitat Autònoma de Barcelona, Españal gabriel.jover@udg.edu,jpujades@ced.uab.es, anamsrodriguez@hotmail.com

\section{Palabras Clave}

Historia rural

Mercado de trabajo

Salarios

Mozos

Mallorca

España

Siglo XVII

\section{KEYWORDS}

Rural History

Labour Market

Wages

Servants

Mallorca

Spain

\section{RESUMEN}

Este estudio quiere contribuir al análisis regional del papel de los criados rurales en el surgimiento de los mercados de trabajo agrarios en la isla de Mallorca en el siglo XVII. El objetivo del artículo es caracterizar los criados rurales del sector olivarero en la isla de Mallorca para mediados del siglo XVII. Las principales fuentes serán los libros de cuentas de los predios del segundo Conde de Formiguera, Ramon Burgués-Saforteza, pues no se disponen de otras fuentes generales o locales de carácter socio-ocupacional. A partir de la sistematización de esa información el estudio sugiere que los mozos en los predios analizados eran trabajadores adultos y mayoritariamente eran contratados por breves períodos de tiempo, lo cual demostraría que tenían unos perfiles sociales y demográficos distintos al de los criados de las regiones europeas del norte donde dominaban los criados rurales jóvenes y solteros con contratos de larga duración.

\section{ABSTRACT}

The present work wants to contribute to the regional analysis of the role of male rural servants in the emergence of the agrarian labour markets based on the case study of the island of Mallorca in the 17th century. The aim of this article is to characterize the male rural servants of the olive sector in the island of Mallorca mid-17th century, where the wage-labour market had developed more extensively and deeply. The main sources will be the account books of the estates of the second Count of Formiguera, Ramon Burgués-Saforteza, since no other general o local sources of social and occupational nature are available. The systematization of this information shows that the male rural servants were adult workers and mostly hired for brief periods of time. So a different social and demographic profile emerges for the Majorcan farm servants in contrast to the one observed in the northern European regions where servants were unmarried young males and were hired for longer periods. 


\section{Criados rurales, mano de obra asalariada y reproducción de las unidades campesinas}

La figura de los criados agrarios o mozos (servants en su acepción inglesa) ha sido objeto de un intenso debate desde los estudios seminales de John Hajnal (1965), Peter Laslett (1983) y Ann Kussmaul (1981). Estos autores sugirieron que esta figura pudo estar relacionada con el desarrollo del llamado modelo matrimonial europeo atlántico, caracterizado por un retraso en la edad al matrimonio como consecuencia de un abandono temprano del hogar familiar para trabajar, normalmente en una explotación ajena antes de formar su propia familia (Dribe \& Lundh, 2005; Snell, 1985). Sin embargo, en el Mediterráneo este patrón no era uniforme y se han pergeñado diversas trayectorias (Sarti, 2007). Dos ejemplos pueden ofrecer los extremos del abanico. En las comarcas nororientales de Cataluña, donde predominaba la explotación campesina familiar extensa (masías), que precisaba la contratación de mano de obra asalariada adicional para su gestión, se desarrolló un mercado de jóvenes mozos que cubrían parte de la demanda de trabajo agrario anual (Garrabou \& Saguer, 1996; Roca, 2005; Saguer \& Coll, 2004). Este modelo se asemejaría al modelo de los criados agrarios (servants) descritos en los trabajos que han estudiado las zonas donde dominaba la tenencia campesina ampliada (Sarasúa, 2005).

Por el contrario, en las zonas latifundistas de La Mancha y la Andalucía Occidental, donde dominaba la gran explotación, fueron los mercados de trabajo a jornal los que tuvieron un papel predominante (Florencio Puntas y López Martínez, 2000ª y 2000b; López Estudillo, 2006). Esta categoría de criados agrarios podía tener trayectorias diversas, en algunos casos esos jóvenes asalariados prolongaron esta ocupación hasta la edad madura (Simón, 2009, pp. 132-133), mientras en otros el joven criado acaba convirtiéndose en jornalero o labrador (García-González, 1998, pp. 162, 164-166, 167-172). Estos estudios ponen de relieve que los criados rurales tuvieron un papel fundamental en la consolidación de las explotaciones campesinas ampliadas, pero más complejo es el papel que tuvo esta categoría sociolaboral donde dominaba la gran explotación con trabajo asalariado.

La isla de Mallorca es un precoz ejemplo del desarrollo de los mercados de trabajo asalariado. Diversos estudios sobre la sociedad rural de los siglos XVI-XVIII han destacado la importancia que tenía la mano de obra jornalera en la oferta de trabajo, así como el destacado papel que tenía en ella la mano de obra femenina e infantil (Albertí \& Morey, 1986; Escartín, 2001; Grau \& Tello, 1985; Jover \& Pons, 2012; Loder \& Moll, 1996; Moll \& Suau, 1979). Sin embargo, se ha soslayado la importancia que tenían los mozos o criados rurales -llamados missatges en la isla- en la estructura laboral de esos predios. Esta figura aparece ya como parte de la mano de obra de las reservas señoriales (Jover, Mas \& Soto, 2002), y en los grandes predios formados en el siglo XV (Montaner \& Le Senne, 1981). No obstante, no se consolidó hasta la primera mitad del siglo XVII, cuando se consolidaron los mercados de trabajo asalariado en la isla (Jover, 2012; Jover \& Pons, 2012, pp. 205-209, 236-238). En los censos agrarios de finales del XVIII los criados representaban un 7\% de las ocupaciones masculinas registradas (Juan Vidal, 1989); y los libros de cuentas de los predios del siglo XVIII muestran que los mozos representaban el $40 \%$ de la mano de obra contratada (Albertí \& Morey, 1986; Jover, 2013a y 2013b). Por tanto, no cabe duda de su peso social y demográfico en la sociedad rural de la isla.

Este estudio quiere contribuir al análisis regional del surgimiento de esos mercados de trabajo agrarios, y en particular al papel que en él jugaron los mozos en las grandes explotaciones mediterráneas que generaban demanda de trabajo asalariado. Dicho estudio se centrará en el sector olivarero, pues era el principal sector exportador de la isla, y donde el mercado de trabajo asalariado se estaba desarrollando más extensa y profundamente. Por último, el estudio se centrará en los libros de cuentas de los predios de la hacienda olivarera Burgués-Safortesa, y en particular en la documentación del predio s’Estorell entre 1652-1680, pues como es sabido para esta etapa no disponemos de otro tipo de fuentes que permitan acercarnos a la estructura sociolaboral agraria. El estudio se estructurará a partir de los siguientes apartados. En el primero se discutirá el alcance de las fuentes estudiadas. En segundo lugar, se describirán las características de las diversas categorías laborales y la duración de los contratos de los mozos. En tercer lugar, se mostrarán las diversas escalas salariales para cada categoría. En cuarto, se examinará el lugar, el origen o procedencia de los mozos contratados. Finalmente, se cierra con unas conclusiones donde se pone el acento en el perfil sociodemográfico de los mozos que sugieren los libros de cuentas. 


\section{Las fuentes: libros de cuentas de los predios y administración de la hacienda}

El segundo conde de Formiguera, Ramon Burgués-Saforteza, en los testamentos de 1689 y 1693 legó al Capítulo de la Catedral una importante hacienda agraria. Este patrimonio estaba integrado por algunas rentas, un molino de agua, huertas, diversos predios cerealistas, y cuatro predios olivareros situados en la Sierra de Tramuntana (Jover, 2015; Montaner \& Le Senne, 1978/79). De este conjunto patrimonial se han conservado numerosos libros de administración general (mayormente libros de albaranes y gasto general) y en menor medida manuales de cuentas de explotación de los predios. La documentación más completa y continuada procede del predio s’Estorell. Este predio estaba situado en el extremo nordeste de la parroquia de Binissalem, al pie de la sierra de Tramuntana. El término tenía una extensión de 3.767 hectáreas y una población de 1.842 habitantes (recuento de 1667). La mayor parte de sus habitantes residían en la villa de Binissalem, y en otros pequeños núcleos rurales (Lloseta, Ayamans y Biniagual). S'Estorell tenía una extensión de 520 ha, que representaba el 14\% de la superficie total del término, y era con diferencia el mayor de los 20 predios que había en la parroquia. Los predios olivareros estaban situados en las primeras pendientes que enlazaban el llano y la sierra, mientras que las pequeñas y medianas explotaciones se arremolinaban en torno a esos núcleos urbanos, en las que se practicaba un cultivo que asociaba el cereal a los cultivos leñosos: vid, algarrobos, almendros y olivos (Jover \& Pons, 2013; Jover, 2015).

Del predio se han conservado los libros de salarios de mozos y jornaleros de los años 1652-1656, 1658-1672 y 1672-1680; los pliegos de gasto de la recogida de la aceituna y la elaboración de aceite de los años 1645-46 y 1658-59 a 1679-80. En los libros de cuentas se anotaban los gastos salariales especificando las diversas modalidades contractuales y remuneración de la labor (jornal, anual, mensual), el nombre y apellido, o apodo, de la mano de obra contratada, su lugar de procedencia, y en algunos casos, a partir de la información registrada, se puede deducir su estado civil y edad (Jover, 2015). Por lo que atañe a la información sobre la contratación de los mozos en los cuadernos de cuentas, el administrador abría una hoja específica para cada mozo (incluido el mayoral) contratado. En la cabecera de la página consta el nombre, labor u ocupación para la que había sido contratado (pastores, hortelanos, etc.) y su remuneración en metálico, haciendo constar el pago del complemento en especies si era el caso. A continuación, se sucedían las anotaciones de los pagos a cuenta del salario especificando la fecha y la cantidad abonada. La cuenta se cerraba cuando el mozo cambiaba de labor, se modificaba su salario o se despedía del predio. Si el mozo renovaba el contrato (es decir continuaba un año más), la relación de pagos continuaba sin más especificaciones. Cuando por algún motivo finalizaba el contrato, el administrador pasaba cuentas con el mozo y descontaba (como "falles", faltas) de su salario los días que se había ausentado. A continuación, se abría otra cuenta para el mozo que sustituía al que se marchaba. Por tanto, los libros de cuentas nos ofrecen las fechas de inicio del contrato (o bien el primer pago efectuado un mes más tarde), y el de finalización del contrato que se correspondía con el último pago realizado, aunque en ocasiones los pagos se demoraban algunas semanas e incluso meses respecto de la fecha de finalización del contrato.

Sin embargo, a pesar de su riqueza, el estudio de los libros de cuentas plantea algunos problemas metodológicos. Por una parte, el conocido problema de representatividad de la fuente (Antoine, 2000). Los libros de cuentas de explotación únicamente abarcan las trayectorias laborales de los mozos contratados en el predio estudiado, en un contexto, como se verá, en el que operaban otros predios, y en un mercado de trabajo que no era local. Aun así, el predio de S'Estorell era el más importante de la hacienda por diversos motivos: por su alto volumen de producción, así como el de contratación de mano de obra (más de 10.000 jornales anuales de media entre 1657 y 1680); el reclutamiento de esta mano de obra se extendía mucho más allá de los límites locales y comarcales (Jover, 2015); era el más extenso del distrito; y, según el catastro de 1685, estaba entre los 5 más rentables de la islaii. 


\section{Grafico 1 Número de mozos contratados anualmente en el predio s’Estorell, 1654-1680}

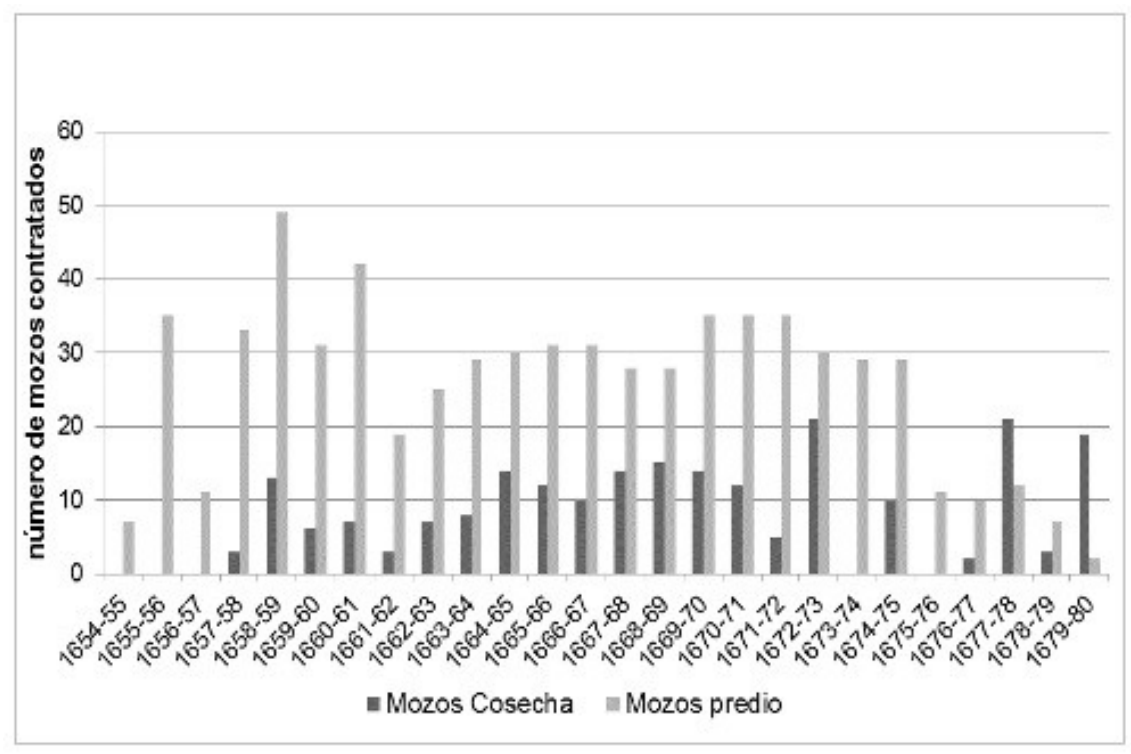

Fuente: ACM legajos 14.223, 14.193, 14.204 y 16.922

Por otra parte, la fuente presenta algunas lagunas documentales. En la figura 1 se han tabulado el número de mozos que cada año eran contratados para las labores generales del predio y para la cosecha de la aceituna y fabricación de aceite. Como puede apreciarse, entre 1654 y 1680 el número de mozos contratados osciló considerablemente. Estas variaciones en el número de contrataciones responden a diversas causas. En primer lugar a las modalidades de gestión. Entre 1645 y 1654 las tierras del predio estuvieron arrendadas y el terrateniente solamente explotaba los olivares directamente. Por tanto, este último solamente contrataba unos pocos mozos para el mantenimiento del predio, pues la mayoría de los aprovechamientos corrían a cargo del arrendatario ${ }^{\text {iii. }}$ En los años 1655-57 el predio fue gestionado directamente, pero un pleito sobre los derechos sucesorios entre la Condesa y la casa Sureda-Çanglada en 1656-1657, puso la gestión del predio en manos del juez que dirimía el pleito. De esos años solamente se ha conservado la documentación completa del año 1655-1656 ${ }^{\text {iv }}$. La plena posesión del predio se recuperó a partir de finales de 1657, y desde 1658 hasta 1686 el predio fue conducido directamente por el terrateniente. Durante ese período el número de mozos contratados cada año se mantuvo en torno a 30 individuos. A partir de 1675 su número descendió a una media de 10 entre 1675-1678, y en los años 1678 y 1680 solamente se registraron entre 3 y 5 contratos. Ello es debido a que el último libro de cuentas (1672-1680) no está completo por lo que respecta a la contratación de los mozos, aunque sí por lo que hace a la contratación de la mano de obra jornalera. Los nuevos mozos contratados a partir de 1675 se anotaron en un nuevo libro que no se ha conservadov. Por tanto, en los años 1675 a 1679 solamente se mantuvieron las cuentas de aquellos ya contratados y se registraron pocos contratos de los nuevos mozos en el cuaderno.

A pesar de estos inconvenientes planteados, la documentación de este predio resulta excepcional tanto por su cronología como por su riqueza informativa. Por ello, hemos utilizado toda la información que nos proporcionan los libros de cuentas del período 1654 y 1679, aun a sabiendas que la de los años 1654-57 no es completa. Así pues, por su extensión y capacidad productiva, el volumen de contratación y su impacto en el territorio circundante, s'Estorell constituye un ejemplo significativo de cómo se desarrolló el mercado de trabajo de los criados agrarios en los predios olivareros a mediados del siglo XVII.

\section{Los mozos del predio s'Estorell de la hacienda Safortesa, 1656-1679}

La condesa primero, y su hijo después, se involucraron de forma directa en la gestión del predio s'Estorell. Durante toda esta etapa la administración de la hacienda agraria fue llevada por el presbítero y beneficiado Jaume Antoni Rubí ${ }^{\text {ii }}$. Por debajo del administrador, los mayorales eran los que llevaban el manejo de las labores agrarias 
y la organización del trabajo en cada uno de los predios de la hacienda. En el cuadro 1 se ha sintetizado la estructura del gasto laboral de s'Estorell. Los gastos de manutención de los asalariados agrarios no se han recogido, porque en su mayor parte procedían de los diferentes aprovechamientos del predio (hortalizas, legumbres, cereales, leña, carne y vino), y no era consignado su valor monetario ${ }^{\text {vii }}$. Tampoco se han incluido los salarios del mayoral, las criadas y los artesanos (herrero, carpintero, talabartero, tejedores e hiladoras, etc.) que trabajaban en o para el predio. Por último, solamente hemos tomado los años en los que las cuentas eran completas, según se ha descrito en el apartado anterior.

\begin{tabular}{|c|c|c|c|}
\hline \multicolumn{4}{|c|}{$\begin{array}{l}\text { Tabla 1. La composición de la demanda de trabajo: gasto monetario de los } \\
\text { salarios pagados a la mano de obra en el predio s'Estorell, 1658-1675 } \\
\text { (Binissalem). }\end{array}$} \\
\hline $\begin{array}{l}\text { Modalidades } \\
\text { contractuales }\end{array}$ & $\begin{array}{l}\text { Promedio } \\
\text { jornales/año }\end{array}$ & $\begin{array}{l}\text { \% Valor gasto } \\
\text { en salarios }\end{array}$ & $\begin{array}{l}\text { \% Número } \\
\text { jornales }\end{array}$ \\
\hline Jornales Femeninos & 3.891 & 25,4 & 38,4 \\
\hline Jornales masculinos & 1.802 & 27,3 & 17,8 \\
\hline Jornales siega y trilla & 239 & 5,3 & 2,4 \\
\hline Mozos & 4.196 & 41,9 & 41,4 \\
\hline Total & 10.127 & 100,00 & 100,00 \\
\hline
\end{tabular}

La composición del gasto en salarios en el predio de s’Estorell entre 1658 y 1676 muestra los dos componentes laborales del predio: los salarios de los mozos y los de la mano de obra jornalera (femenina, masculina e infantil), a la que debemos añadir la contratación de la mano de obra para la siega, que generalmente merecía un tratamiento diferenciado en los libros de cuentas. Los mozos representaban el 41,9 \% del gasto en salarios, $\mathrm{y}$ también, el 41,4 \% de la ocupación medida en número de jornales anuales realizados. Según los testimonios coetáneos, la jornada laboral se iniciaba al alba y terminaba a la puesta de sol, de lunes a sábado incluidos; el domingo no era laborable. Así, la media de días trabajados anualmente por los mozos se acercaba a los 280-300 (Jover \& Pons, 2012, pp. 205-207). Esta estructura del gasto en salarios monetarios de s’Estorell es semejante a la observada para otros predios cerealistas y olivareros de la época (Albertí \& Morey, 1986, pp. 37-38; Bisson, 1977, pp. 13-219; Grau \& Tello, 1985, pp. 68-70;; Jover \& Pons, 2012; Jover, 2013).

Según los libros de cuentas, cada año se precisaban en promedio 15 mozos a tiempo completo (aproximadamente 288 días de trabajo por mozo) para el desempeño de las labores agrarias. Sin embargo, como se ha mostrado en el gráfico 1, el número de mozos contratados anualmente era mucho más elevado, en torno a 30, y el número de contratos variaba de un año a otro. Ello era debido, como se verá, a dos factores: por una parte, a la estacionalidad de las labores y a la elevada tasa de rotación en la contratación de los mozos; y, por otra, en parte, a las oscilaciones de las cosechas. Respecto al primer rasgo, los estudios sobre los mozos han destacado que esta no era una categoría laboral homogénea. Por una parte, se ha distinguido aquel grupo de mozos contratados para todo el año agrícola, llamados missatges, que residía en el predio y realizaba todo tipo de labores. En este grupo se desarrolló una cierta jerarquía laboral. Por otra parte, estaban aquellos otros mozos contratados para labores específicas y de carácter estacional (Albertí \& Morey, 1986; Jover \& Pons, 2012, pp. 205-210; Loder \& Moll, 1996; Moll, 1987; Montaner \& Le Senne, 1981). 


\begin{tabular}{|c|c|c|c|c|}
\hline $\begin{array}{l}\text { Categorías } \\
\text { Sociolaborales }\end{array}$ & $\begin{array}{l}\text { \% Contrato } \\
\text { anual }\end{array}$ & $\begin{array}{l}\% \\
\text { Contrato a } \\
\text { jornal }\end{array}$ & $\begin{array}{l}\text { \% Contrato } \\
\text { mensual }\end{array}$ & $\begin{array}{l}\text { \% } \\
\text { Total }\end{array}$ \\
\hline Mozos predio & 3,4 & & 31,3 & 34,6 \\
\hline Labradores & 0,9 & 0,1 & 19,4 & 20,5 \\
\hline Hortelano & 6,1 & & 5,1 & 11,3 \\
\hline Vigilante viñas & 0,0 & & 2,1 & 2,1 \\
\hline Carriceros & 0,3 & & 5,1 & 5,4 \\
\hline Pastores & 0,0 & & 2,5 & 2,5 \\
\hline Maestros Almazara & 0,0 & & 10,3 & 10,3 \\
\hline Trajineros Almazara & 1,1 & 0,1 & 6,8 & 7,9 \\
\hline Mayorales mujeres & 0,0 & & 5,4 & 5,4 \\
\hline Total & 11,9 & 0,1 & 88,0 & 100,0 \\
\hline
\end{tabular}

La tabla 2 muestra la estructura sociolaboral de los mozos en el predio s’Estorell durante el período 1654-1680. Los porcentajes sintetizan la distribución del tiempo de trabajo contratado para cada una de las categorías, medido en meses completos o fracciones. La distribución de los mozos por categorías muestra que los missatges, aquellos mozos contratados para todo el año agrícola, solamente representaban poco más de un tercio (34,6 \%) del tiempo trabajado por el total de los mozos contratados. Los otros dos tercios correspondían a mozos contratados para labores específicas de carácter anual, como el hortelano (11,3\%), y sobre todo para labores que tenían en su mayor parte un marcado carácter estacional: sembrar y labrar barbechos (labradores con un 21\%), las actividades silvopastorales (pastores y carriceros con un 8\%), la viticultura (vinyòvol con el 2\%) y la elaboración de aceite (trajineros, mozos y maestros de almazara con el 24\%). Esta elevada participación de los mozos estacionales en la demanda de trabajo anual del predio explica el elevado número de contrataciones medias anuales que se han comentado en el Gráfico 1.

En las filas de la tabla 2 se sintetiza la información sobre la duración nominal de los contratos. Esta se ha establecido a partir de la modalidad de remuneración monetaria de cada categoría sociolaboral. Es decir, la clasificación de la duración de los contratos se ha hecho a partir del período para el que se fijaba la remuneración: si el salario era anual o mensual. Como muestra la última fila de la tabla, la modalidad de contratación más frecuente en esa época era la mensual: el 88\% de los mozos eran contratados por meses. Solamente el hortelano (6,14\%) y algunos mozos de confianza, como el carretero (3,3\% de los contratos de mozos), eran contratados por años y su salario se establecía anualmente. Como se verá posteriormente, este rasgo puede atribuirse a la elevada rotación de los mozos; aunque el predominio del contrato mensual no era óbice para que esos mozos prolongaran su contrato a lo largo de todo el año, e incluso a lo largo de muchos años.

La tabla 3 precisamente quiere ponderar esta última cuestión. El cuadro sintetiza las 303 trayectorias laborales de los mozos documentados que fueron contratados entre 1654 y 1680, sin distinguir categorías. El propósito es captar la permanencia de los mozos, independientemente de si cambiaban o no su ocupación laboral a lo largo del período estudiado: un mozo podía ser missatge por un tiempo y después continuar como labrador o mozo de almazara. Para analizar la información hemos ordenado la duración del contrato de cada mozo por intervalos mensuales (columna 1), siguiendo primero una división trimestral de los intervalos, adecuada a la estacionalidad 
de algunos de los contratos, y después anual. Las columnas 2 y 3 muestran el número de mozos y los meses que trabajaron para cada uno de los intervalos. En las siguientes columnas se ha calculado para cada intervalo la media de meses trabajada por cada mozo de ese intervalo (4), y en la columna siguiente el número de años distintos en que ese mozo fue contratado (5), aunque no fuera para el año completo, sino por diversos meses. Como se verá, ello tiene relevancia para entender la continuidad en la contratación estacional de determinados mozos. Las dos últimas columnas muestran el porcentaje de mozos (6) y meses trabajados (7) para cada intervalo respecto del total.

El resultado de este primer ejercicio confirma lo que se había anunciado anteriormente: 161 mozos, el 53,4\% de la muestra estudiada, comprendidos en los intervalos 1-3 y 4-6, trabajaron menos de medio año en el predio (columna 4), y en su mayor parte solamente lo hicieron una vez a lo largo del período estudiado (columna 5). Sin embargo, esos mozos solamente estuvieron contratados por el 12,9\% del total de los meses trabajados en el período documentado. En los dos intervalos superiores (7-9 y 10-12) el número (69) y porcentaje (22,8\%) de mozos desciende notablemente, y la proporción de los meses trabajados respecto del total era del 15,6\%. Sin embargo, debemos hacer notar que el número medio de meses trabajado por cada mozo aumenta significativamente respecto de los intervalos anteriores (6,4-7,8 meses de media), y en una proporción significativa muchos de ellos trabajaron más de un año en el predio (columna 5). Por tanto, había un conjunto de mozos que, a pesar de trabajar solamente durante un período de 6-8 meses, lo hicieron en más de un año.

\begin{tabular}{|c|c|c|c|c|c|c|}
\hline $\begin{array}{l}\text { Meses } \\
\text { de } \\
\text { contrato } \\
\text { (1) }\end{array}$ & $\begin{array}{l}\text { Número } \\
\text { mozos } \\
\text { Contratados } \\
\text { (2) }\end{array}$ & $\begin{array}{l}\text { Meses } \\
\text { trabajados } \\
\text { por } \\
\text { intervalo } \\
\text { (3) }\end{array}$ & $\begin{array}{l}\text { Media de } \\
\text { meses } \\
\text { contratados } \\
\text { cada año (4) }\end{array}$ & $\begin{array}{l}\text { Media de } \\
\text { años } \\
\text { contratados } \\
\text { Mozo (5) }\end{array}$ & $\begin{array}{l}\% \text { Número } \\
\text { mozos } \\
\text { Total (6) }\end{array}$ & $\begin{array}{l}\% \quad \text { Meses } \\
\text { trabajados } \\
\text { por cada } \\
\text { intervalo (7) }\end{array}$ \\
\hline $1-3$ & 88 & 173 & 1,9 & 1,0 & 29,0 & 4,3 \\
\hline $4-6$ & 74 & 344 & 4,5 & 1,1 & 24,4 & 8,6 \\
\hline $7-9$ & 39 & 295 & 6,4 & 1,3 & 12,9 & 7,4 \\
\hline $10-12$ & 30 & 326 & 7,8 & 1,7 & 9,9 & 8,2 \\
\hline $13-24$ & 28 & 504 & 7,7 & 2,8 & 9,2 & 12,6 \\
\hline $24-48$ & 28 & 1.003 & 8,1 & 4,9 & 9,2 & 25,2 \\
\hline \multirow[t]{2}{*}{+49} & 16 & 1.339 & 9,7 & 8,9 & 5,3 & 33,6 \\
\hline & 303 & 3.984 & 6,6 & 3,1 & 100,0 & 100,0 \\
\hline
\end{tabular}

A partir del intervalo 13-24 y sucesivos, el número y proporción de mozos para cada intervalo se reduce; en cambio, su aportación a la contratación total de trabajo del predio y su continuidad en el predio se incrementan. Las características de esos tres intervalos pueden sintetizarse de la siguiente manera. En primer lugar, los 72 individuos comprendidos en esos intervalos representaban el 23,7\% de los mozos documentados, y aportaron el 71,4\% de los meses de trabajo. Es decir, un reducido número de mozos dio cierta continuidad al esqueleto laboral de ese predio. En segundo lugar, esos mozos trabajaban de media entre 7,7 y 9,7 meses al año en el predio, lo que sugiere que si se descuentan los días que se ausentaban, fiestas u otras faltas diversas, eran mozos a tiempo completo en el predio. Por último, estos mozos tuvieron una relación larga con el predio: los 28 mozos del intervalo 13-24 meses fueron contratados de media por dos años o más; los 28 del intervalo 24-48 lo fueron de 
media por casi 5 años; y los del último intervalo por más de ocho años. Es decir, algunos mozos estuvieron contratados en el predio durante largos períodos; sin embargo, ello no significaba que todos estuvieran contratados por un año completo.

\section{Grafico 2 Meses de inicio y finalización de los contratos de los mozos del predio s’Estorell}

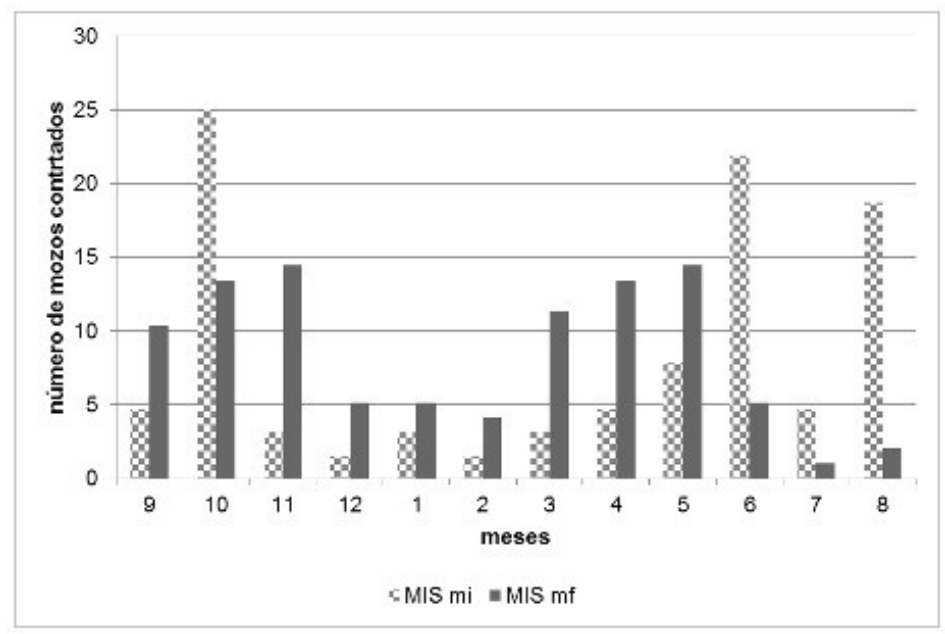

Fuente: ACM legajos 14.223, 14.193 y 14.204

En las tablas 4 y 5, siguiendo la misma estructura de la tabla 3, y en las figuras 2 y 3, se pretende poner de relieve las causas de las diferencias entre la contratación anual y mensual de dos de las categorías observas en el cuadro: los mozos para toda labor o anuales, y los mozos labradores como ejemplo de la contratación estacional. La primera categoría estaba constituida por aquellos mozos (missatges) contratados "per tota feina” (para todo trabajo), que se dedicaban a las labores agrarias que exigían los cultivos y el ganado del predio. El gráfico 2 muestra que había dos máximos de inicio de la contratación (MISmi): uno que va de agosto a octubre, y otro en junio y julio. La primera punta de contratación, meses de agosto a octubre, coincide con dos fechas señaladas: el 8 de setiembre, festividad de la Mare de Deu dels missatges, y el 29 de setiembre, San Miguel, fecha en que se iniciaban los contratos agrarios (Moll \& Suau, 1979). En ese mes se iniciaba la actividad agraria: se labraban los barbechos (aunque esta actividad se iniciaba en agosto) antes de la siembra, se recogían las algarrobas (setiembre) y posteriormente las aceitunas (octubre). Las variaciones en esos tres meses eran debidas a que los mozos no se contrataban todos a la vez, sino según las necesidades y las bajas que se producían en esos meses. El pico del mes de junio coincide con la cosecha de cereales. Esta segunda punta era provocada por dos movimientos: las bajas de aquellos mozos que abandonaban el predio para contratarse como segadores en los predios cerealistas del centro de la isla ${ }^{\text {viii }}$, que debían ser reemplazados por nuevos mozos, y un refuerzo laboral para la trilla de los cereales. Las bajas, o la finalización de contratos (MISmf), coincidían también con esas dos puntas. Las bajas se producían en los meses de setiembre a octubre, y nuevamente en los meses de marzo a junio cuando la recogida de la aceituna había terminado y muchos mozos se despedían para acudir a la siega, algunos de los cuales se reincorporaban en setiembre. Sin embargo, como se puede apreciar en el gráfico, a lo largo de todo el año se sucedían altas y bajas por motivos no especificados en los cuadernos de cuentas. 


\begin{tabular}{|l|l|l|l|l|}
\hline \multicolumn{5}{|l|}{$\begin{array}{l}\text { Tabla 4. Duración de los contratos de los mozos (missatges) en el } \\
\text { predio s'Estorell, 1654-1679. Mozos contratados para todo el año. }\end{array}$} \\
\hline $\begin{array}{l}\text { Meses de } \\
\text { contrato }\end{array}$ & $\begin{array}{l}\text { Número } \\
\text { mozos }\end{array}$ & $\begin{array}{l}\text { Media de } \\
\text { meses } \\
\text { contratados } \\
\text { cada año }\end{array}$ & $\begin{array}{l}\text { Media de } \\
\text { años } \\
\text { contratados }\end{array}$ & $\begin{array}{l}\text { Porcentaje } \\
\text { mozos }\end{array}$ \\
\hline $1-3$ & 34 & 1,6 & 1,0 & 31,5 \\
\hline $4-6$ & 23 & 4,5 & 1,0 & 21,3 \\
\hline $7-9$ & 11 & 6,2 & 1,2 & 10,2 \\
\hline $10-12$ & 7 & 7,3 & 1,4 & 6,5 \\
\hline $13-24$ & 18 & 8,0 & 2,3 & 16,7 \\
\hline $25-48$ & 9 & 7,5 & 4,8 & 8,3 \\
\hline+48 & 6 & 9,0 & 7,5 & 5,6 \\
\hline Total/media & 108 & 6,3 & 2,7 & 100,0 \\
\hline Fuentes : ACM $14.223,14.193$ y 14.204 & \\
\hline
\end{tabular}

La tabla 4 sintetiza la permanencia de los mozos (missatges) siguiendo la misma estructura que en la tabla 3 . El número de missatges contratados en el predio para todo el año agrícola fueron 108, un poco más de un tercio de los mozos totales. Más de la mitad de ellos (53\%) lo estuvieron por un período inferior a los 7 meses (intervalos 13 y 3-6 meses). De hecho, 34 mozos fueron contratados por un mes y medio, y otros 23 por 4 meses y medio de media, y todos ellos a lo sumo solamente fueron contratados por una sola vez a lo largo del período estudiado. Un grupo más reducido, los 18 mozos comprendidos en los intervalos de 7-9 y 10-12 meses, tuvieron una continuidad mayor en la ocupación, ya que estuvieron contratados de media 6-7 meses cada año, y en algunos casos repitieron el contrato como mínimo otro año (medias de años 1,2 y 1,4 en esos intervalos). Por encima de ellos encontramos 18 mozos que fueron contratados por un año o más (intervalo de 13-24 meses), y que en su mayoría trabajaron de media cada año 8 meses y repitieron el contrato un mínimo de 2 años de media distribuidos entre dos años o algo más; es decir, su contrato pudo ser más breve en algún año y extenderse a un tercero. Por último, 15 individuos de los dos últimos intervalos (25-48 y +48 meses) trabajaron en el predio de media entre 7,5 y 9 meses al año, y lo hicieron a lo largo de entre 4 y 7 años. Por tanto, podemos decir que fueron un puñado de individuos, 33 mozos, los que acapararon el grueso de la contratación laboral en el período estudiado, y que constituyeron el esqueleto organizativo y laboral del predio. 


\section{Grafico 3 Meses de inicio y finalización de los contratos de los mozos de labranza predio s'Estorell. Porcentajes respecto del total del período, 1654-1679}

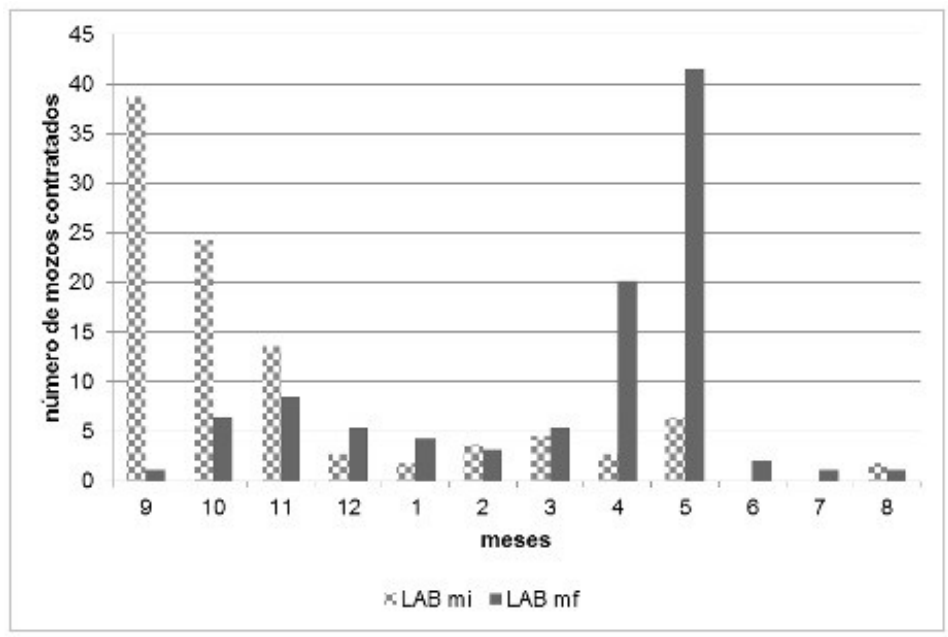

Fuente: ACM legajos 14.223, 14.193 y 14.204

Los mozos de labrar eran el segundo contingente laboral en importancia del predio, con cerca del $21 \%$ del volumen de trabajo (tabla 1). Como muestra el gráfico 3, el inicio de su contrato se iniciaba en setiembre y finalizaba a finales de abril o principios de mayo. Su labor consistía en labrar los barbechos y las sementeras de olivos con los tiros de mula del predio. Cada año se contrataban de media unos 10 mozos para labrar, de los cuales había 5 o 6 que labraban a la vez, y el resto eran las sustituciones realizadas por motivos no especificados, pues el administrador se limitaba a escribir que “dejaban” el predio.

\begin{tabular}{|l|l|l|l|l|l|l|}
\hline \multicolumn{6}{|l|}{ Tabla 5. Duración de los contratos de los mozos de labranza (Ilauradors) en el predio s'Estorell, } \\
1654-1679. Contratados para labrar entre setiembre y mayo.
\end{tabular}

La tabla 5, así como como la figura 3, muestran la marcada estacionalidad de este tipo de contrato. Los 59 “llauradors" de los 3 primeros intervalos (71\% del total) fueron contratados para unos pocos meses, de hecho en su mayoría fueron contratados para un único año y no repitieron contrato en años sucesivos. Nuevamente, de los 84 individuos documentados sólo un reducido número de ellos fueron contratados para toda la labor de labrar (setiembre a abril) y lo fueron a lo largo de diversos años, no necesariamente continuos. Este era un grupo de 25 
individuos que representa 29,8\% del total de mozos de labranza consignados en los libros de cuentas, aunque trabajaron más de dos años en el predio, y lo hicieron en el 61,7\% de los meses de contrato documentados para este período. Sin embargo, no dejaba de ser una labor ocasional y no parece que tuviera una permanencia continuada en este predio para la gran mayoría de los mozos documentados.

Por tanto, los datos del predio s’Estorell permiten la siguiente caracterización del mercado de trabajo de los mozos. En primer lugar, ese mercado muestra una clara dualidad en las tipologías contractuales de los mozos: solamente un tercio de los mozos, llamados missatges en la documentación, eran contratados para todo el año y residían de forma permanente en el predio, realizando todo tipo de labores agrarias; el resto de los mozos eran contratados con carácter estacional para el desempeño de labores específicas, como labrar (llauradors), mozos de almazara, mayorales de mujeres, carriceros, etc. En segundo lugar, tanto los missatges como los otros mozos presentan una elevada rotación y escasa permanencia en el predio. De esta manera, la elevada rotación implicaba la contratación de un elevado número de individuos de las villas circundantes al predio, para relativamente breves períodos de tiempo. Por último, un porcentaje reducido de mozos tuvo una elevada continuidad en la ocupación y una elevada permanencia en el predio. Así pues, la mayor parte de las tipologías descritas no parece que se puedan asimilar al modelo de life-cycle servants descrito para Inglaterra u otras regiones atlánticas (Kussmaul, 1981).

\section{La remuneración del trabajo de los mozos}

La remuneración del trabajo de los mozos era compleja, pues atendía a diferentes criterios: edad, experiencia, intensidad del trabajo y cualificación. Además, el salario incorporaba en algunas ocupaciones unos ingresos complementarios en forma de alimento y alojamiento (Albertí \& Morey, 1986; Molina, 2003). Los mozos permanentes o missatges recibían alimentos y alojamiento en el predio. Los trabajadores de la almazara, los mayorales que conducían los tajos de cogedoras y los trajineros, además de los salarios en metálico, eran alimentados y alojados por el terrateniente (dormían en la misma almazara o en los establos del predio). El maestro de la almazara además de la alimentación recibía una cantidad de aceite y una parte de la ceniza para la elaboración de jabón. Por último, había algunos mozos que no recibían alojamiento ni la alimentación completa (sino parte de ella). Los hortelanos recibían, además del salario en metálico, una barchilla de trigo cada semana, y residían en las casas anexas a los huertos de s'Estorell. Por último, los labradores además del salario en metálico posiblemente recibían un complemento al pan que ellos llevaban, básicamente verduras, pescado salado y legumbres (companatge) ${ }^{\mathrm{ix}}$. En este apartado nos centraremos en el análisis de la remuneración en metálico ya que es la que más claramente definía las diferencias entre los mozos que se contrataban para una misma labor.

La tabla 6 resume las remuneraciones monetarias mensuales medias por períodos de diez años de las principales categorías de mozos del predio s’Estorell para el período estudiado. Aunque el cuadro muestra una tendencia descendente de todos los salarios en la etapa estudiada, el propósito de este apartado no es el estudio de la evolución de los salarios, sino mostrar que la estructura salarial se mantuvo relativamente constante a lo largo de esta etapa. La estructura salarial muestra que había diferencias claras en el salario medio de cada una de las principales ocupaciones. Las ocupaciones mejor remuneradas eran aquellas que exigían una mayor cualificación, como era la de hortelano y maestro de almazara, o bien las que tenían la confianza del terrateniente, como la de carretero y mayoral de mujeres. En un nivel inferior estaban aquellos para los que si bien se podía exigir una cierta experiencia, el trabajo no exigía una elevada cualificación, como eran los operarios de la almazara, los labradores y los missatges. Por debajo solamente había dos ocupaciones que eran remuneradas con un salario muy inferior: el salario del trajinero de sacos y el pastor.

Tabla 6. Salarios monetarios de los mozos del predio s'Estorell por categorías en sueldos medios mensuales (sueldos de Mallorca/mes).

\begin{tabular}{|l|l|l|l|l|}
\hline Media período & $\begin{array}{l}\text { Carricero } \\
\mathrm{s} \\
\mathrm{s} / \mathrm{mes}\end{array}$ & $\begin{array}{l}\text { Mozos } \\
\mathrm{s} / \mathrm{mes}\end{array}$ & $\begin{array}{l}\text { Hortelano } \\
\mathrm{s} / \mathrm{mes}\end{array}$ & $\begin{array}{l}\text { Labrador } \\
\mathrm{s} / \mathrm{mes}\end{array}$ \\
\hline
\end{tabular}




\begin{tabular}{|l|l|l|l|l|}
\hline $1652-1660$ & 58 & 55 & 64 & 56 \\
\hline $1661-1670$ & 51 & 45 & 59 & 50 \\
\hline $1671-1680$ & 45 & 39 & 51 & 47 \\
\hline Media período & Mayoral & Mozos & Maestro & Trajinero \\
\hline & mujeres & almazara & almazara & sacos \\
\hline $1652-1660$ & 53 & 50 & 69 & 30 \\
\hline $1661-1670$ & 56 & 45 & 83 & 19 \\
\hline $1671-1680$ & 59 & 45 & 73 & 19 \\
\hline $\begin{array}{l}\text { Fuentes: ACM } \\
\text { moneda de cuenta. }\end{array}$ & & & \\
\hline
\end{tabular}

Ahora bien, las medias ocultan en algunos casos desviaciones en las remuneraciones dentro de una misma categoría. Estas diferencias en la remuneración en una misma ocupación se han recogido en la tabla 7 . La tabla recoge para cada una de las ocupaciones los diferentes salarios monetarios en tramos de 5 sueldos, que era el escalón que el mismo administrador utilizaba para diferenciar las remuneraciones entre los diferentes mozos. Si el cuadro 6 sugiere una remuneración distinta en función de la cualificación en las ocupaciones de los mozos, la información de la tabla 7 permite apreciar si en cada una de las categorías laborales se establecía una diferenciación por experiencia, destreza o edad del trabajador.

\begin{tabular}{|c|c|c|c|c|c|c|c|}
\hline \multicolumn{8}{|c|}{$\begin{array}{l}\text { Tabla 7. Las diferentes escalas de remuneración salarial monetaria para las diferentes } \\
\text { ocupaciones del predio s'Estorell (1658-1679) }\end{array}$} \\
\hline Intervalos salarios & $\begin{array}{l}\text { Mozos } \\
\text { labrar }\end{array}$ & $\begin{array}{l}\text { Mozos } \\
\text { predio }\end{array}$ & $\begin{array}{l}\text { Mozo } \\
\text { almazara }\end{array}$ & $\begin{array}{l}\text { Maestro } \\
\text { almazara }\end{array}$ & $\begin{array}{l}\text { Trajinero } \\
\text { sacos }\end{array}$ & $\begin{array}{l}\text { Mayoral } \\
\text { mujeres }\end{array}$ & Hortelano \\
\hline Sueldos/mes & $\mathrm{N}$ & $\mathrm{n}$ & $\mathrm{n}$ & $\mathrm{n}$ & $\mathrm{n}$ & $\mathrm{N}$ & $\mathrm{n}$ \\
\hline $10-15$ & & 6 & & & 7 & & \\
\hline $20-25$ & & 22 & & & 29 & & 4 \\
\hline $30-35$ & 14 & 20 & 4 & & & & \\
\hline $40-45$ & 27 & 63 & 59 & & & 5 & \\
\hline $50-55$ & 119 & 73 & 19 & & & 11 & 17 \\
\hline $60-70$ & 48 & 19 & & 14 & & 28 & \\
\hline $80-100$ & & & & 8 & & 1 & \\
\hline Total (n) & 208 & 203 & 82 & 22 & 36 & 45 & 21 \\
\hline Intervalos salarios & $\begin{array}{l}\text { Mozos } \\
\text { labrar }\end{array}$ & $\begin{array}{l}\text { Mozos } \\
\text { predio }\end{array}$ & $\begin{array}{l}\text { Mozo } \\
\text { almazara }\end{array}$ & $\begin{array}{l}\text { Maestro } \\
\text { almazara }\end{array}$ & $\begin{array}{l}\text { Trajinero } \\
\text { sacos }\end{array}$ & $\begin{array}{l}\text { Mayoral } \\
\text { mujeres }\end{array}$ & Hortelano \\
\hline Sueldos/mes & $\%$ & $\%$ & $\%$ & $\%$ & $\%$ & $\%$ & $\%$ \\
\hline $10-15$ & 0 & 3,0 & 0 & 0 & 19,4 & 0 & 0 \\
\hline $20-25$ & 0 & 10,8 & 0 & 0 & 80,6 & 0 & 19 \\
\hline $30-35$ & 6,7 & 9,9 & 4,9 & 0 & 0 & 0 & 0 \\
\hline $40-45$ & 13,0 & 31,0 & 72 & 0 & 0 & 11,1 & 0 \\
\hline $50-55$ & 57,2 & 36 & 23,2 & 0 & 0 & 24,4 & 81 \\
\hline $60-70$ & 23,1 & 9,4 & 0 & 63,6 & 0 & 62,2 & 0 \\
\hline $80-100$ & & & 0 & 36,4 & 0 & 2,2 & 0 \\
\hline
\end{tabular}




\begin{tabular}{|l|l|l|l|l|l|l|l|}
\hline$(\%)$ & 100 & 100 & 100 & 100 & 100 & 100 & 100 \\
\hline Fuentes : ACM 14.223, 14.193, 14.204 y 16.922 & & & & \\
\hline
\end{tabular}

Los datos de la tabla muestran que había ocupaciones que por motivos distintos concentraban la remuneración monetaria en una estrecha escala salarial y, por otra parte, que había notables diferencias en los niveles de remuneración en una misma ocupación. En el primer modelo encontramos algunas ocupaciones en que los salarios se concentraban en uno o dos tramos. Así, la remuneración de los hortelanos se concentraba en el $81 \%$ de los casos en un único tramo de 50-55 s/mes, lo que sugiere que los trabajadores contratados ya tenían una cierta experiencia en el oficio. El tramo inferior, 20-25 sueldos, era un ayudante del hortelano que en este predio era normalmente su hijo. Semejante interpretación se puede hacer en el caso de los mozos contratados para labrar los olivares, en un 70\% se concentraba en los tramos salariales de 40-45 y 50-55 s/mes. En estas ocupaciones, por su marcado ritmo estacional e intensidad, el terrateniente no estaba interesado en contratar trabajadores poco diestros, o bien en invertir en su aprendizaje. Por ello, es posible que esos mozos fueran en su mayor parte adultos.

En una posición intermedia se sitúan los mozos contratados para la cosecha de la aceituna y la fabricación del aceite. En estas ocupaciones se observa un claro escalado salarial en función de la ocupación. Los sueldos más bajos respondían a una ocupación sin cualificación y que realizaban los muchachos o chicos: el trajín de los sacos de los olivares a la almazara. En un segundo nivel salarial encontramos a los operarios de la almazara (mozo almazara) que ayudaban a los maestros aceiteros que ocupaban la cúspide de la remuneración. Entre ambos se situaba el salario de los mayorales que supervisaban el rendimiento de las cuadrillas de cogedoras. En este caso la diferenciación entre baja cualificación y edad, y un aumento de la cualificación o responsabilidad en el trabajo y la edad, parece clara. Incluso esa escala podía dar lugar a un cierto ascenso en esas ocupaciones desde la juventud a la madurez ejerciendo las diferentes tareas.

La situación es distinta en los mozos contratados para todo tipo de trabajos y que residían en el predio durante el tiempo en que estaban contratados. En este caso el abanico salarial es mucho más amplio, y se debe notar que el número de contratos en los tramos salariales inferiores es elevado. En esta ocupación la documentación explicita en algunos casos que los contratados con remuneraciones inferiores eran niños (10-15 sueldos) o jóvenes (20-25 sueldos). Estos realizaban labores de apoyo como aguadores durante la siega, llevaban la comida a los tajos de mozos y jornaleros que trabajaban en el predio, o bien vigilaban las piaras de cerdos, pavos y burras del predio; posiblemente, a medida que crecían y permanecían en el predio, su remuneración iba aumentando. El salario de entre 30-35 sueldos podría dar cabida a los mozos más jóvenes y menos experimentados. Esta progresión culminaba en el salario de un mozo adulto que oscilaba entre 40-50 sueldos mensuales. Por encima se encuentran los mozos de confianza del mayoral o administrador: los carreteros. Estos cobraban 60-65 sueldos/mes.

Por tanto, de la estructura salarial se puede intuir/inferir que en la mayoría de las labores los mozos eran adultos, y que las trayectorias de progreso en las labores estacionales, excepto como se ha visto en las labores de la almazara, eran limitadas. Solamente entre el contingente de los mozos permanentes, missatges, podemos intuir una cierta diferenciación por edad avalada por la documentación misma cuando llama al·lot, chico, a los mozos jóvenes. A pesar de ello, estos eran una pequeña proporción de los mozos del predio. En su mayor parte parecen ser adultos, pues en el libro de salarios el administrador cuando se efectuaban los pagos del salario hacía constar a quien entregaba el dinero, y en muchos casos era la mujer del mozo ${ }^{\mathrm{x}}$, una hija o hijo ${ }^{\mathrm{xi}}$, o bien otro pariente ${ }^{\mathrm{xii}}$ que lo percibía. Esta estructura salarial sugiere pues que quizás en esta época una proporción elevada de los mozos del predio s'Estorell, y posiblemente también de los predios olivareros de la isla, fueran adultos y no niños o jóvenes, tal como sucedía en los masos catalanes (Roca, 2005) o en las heredades de los yeomen ingleses (Kussmaul, 1981).

Por último, la evolución de los salarios monetarios nominales presentados en la tabla 6 es semejante a la de los mozos de los predios cerealistas: una tendencia general al descenso del salario nominal monetario de los mozos en un contexto de descenso de los precios de los alimentos, ello suponía un aumento del salario real de los mozos. 
Sin embargo, en la misma etapa el aumento del salario nominal y real de la mano de obra jornalera convertía la contratación de la mano de obra jornalera masculina en la opción más costosa para los terratenientes (Jover \& Pons, 2012, pp. 246-249). Así, podemos sugerir que el aumento de la contratación de mozos permanentes o estacionales, junto a la substitución de la mano de obra jornalera masculina por femenina e infantil, pudiese convertirse para los terratenientes en una opción más ventajosa que contratar mano de obra jornalera masculina. En este ejemplo, y en los predios cerealistas del centro de la isla, el descenso o estabilidad del salario monetario de los mozos, y el acusado descenso de los precios de los alimentos -por tanto, del mantenimiento de los mozos o de la parte en especies de su salario-, pudo tener como efecto combinado el de reducir los costes de la contratación de los mozos. Además, la residencia de los mozos en el predio permitía una mayor disponibilidad total de su tiempo de trabajo. En ese contexto pudo explicarse la rápida disminución de la contratación de jornaleros masculinos, el aumento de la demanda de trabajo femenino e infantil y de los mozos permanentes o estacionales (Jover \& Pons, 2012, pp. 224-238). Este rasgo no era una peculiaridad de la isla, sino que fue un movimiento mucho más amplio en aquella etapa de depresión de los precios de los alimentos (1640-1740), particularmente en las zonas donde los mercados de mozos o criados rurales tenían cierta importancia (Kussmaul, 1981; Roca, 2005).

\section{La procedencia de los mozos contratados en s'Estorell}

En su tratado de Art de conró, Montserrat Fontanet (Juncosa \& Martínez, 1747/1979), arrendatario y mayoral de predios cercanos a s’Estorell, ofrece algunos consejos sobre la contratación de los mozos. Más allá de las cualidades morales que se les debía exigir y el trato paternal que debía ejercer el terrateniente, uno de los consejos del autor era: "missatges de prop, si no hi ha altre remei”, es decir, a los mozos mejor contratarlos de poblaciones lejanas al predio que de cercanas. Este consejo tenía que ver con consideraciones económicas y de supervisión de la mano de obra. Sin embargo, en el mismo tratado se ponen de relieve las dificultades que entrañaba ese consejo, pues él mismo da noticia de que los mozos en muchos casos estaban casados, vivían en las villas cercanas y frecuentemente se ausentaban para otros menesteres.

Una imagen semejante proporciona la detallada información del predio s’Estorell. En el cuadro 8 se ha sintetizado la información sobre la procedencia de los mozos que trabajaron en el predio en el período estudiado. El cuadro distingue en la primera columna de la izquierda los distritos de procedencia de los mozos. La misma parroquia de Binissalem (núcleos de Binissalem y Lloseta); las parroquias cercanas (limítrofes) que limitaban con el predio (Alaró, Selva) y no distaban a más de una hora de distancia a pie; aquellas de la sierra de Tramuntana, más alejadas del predio; a continuación el distrito del Pla, el centro de la isla, básicamente la villa de Santa Margalida, y en menor medida a villas cercanas a esta como Llubí (de la parroquia de Muro) y Sa Pobla, situadas entre 20-30 km del predio; y al final los distritos del este de la isla, situados en la zonas del Llevant y Migjorn, a unos 40-50 km del predio. Las columnas del cuadro diferencian la procedencia por cada ocupación y los totales se refieren a las columnas anteriores.

Tabla 8. Procedencia de los mozos contradosen el predio s’Estorell, 1658-1680

\begin{tabular}{|l|l|l|l|l|l|l|l|l|}
\hline $\begin{array}{l}\text { Distritos } \\
\text { procendencia }\end{array}$ & $\begin{array}{l}\text { Pastores, } \\
\text { carriceros }\end{array}$ & $\begin{array}{l}\text { Mozos } \\
\text { Labrar }\end{array}$ & $\begin{array}{l}\text { Mozos } \\
\text { predio }\end{array}$ & Total & $\begin{array}{l}\text { Mozos } \\
\text { molino }\end{array}$ & $\begin{array}{l}\text { Trajinero } \\
\text { sacos }\end{array}$ & $\begin{array}{l}\text { Mayoral } \\
\text { Mujeres }\end{array}$ & $\begin{array}{l}\text { Total } \\
\text { molino }\end{array}$ \\
\hline Parroquia & 6,0 & 11,0 & 25,5 & 42,5 & 6,6 & 16,6 & 0,0 & 23,3 \\
\hline Limítrofes & 3,0 & 5,0 & 21,4 & 29,4 & 16,9 & 2,9 & 21,6 & 41,4 \\
\hline Sierra Tramuntana & 0,4 & 0,0 & 0,4 & 0,7 & 0,6 & 1,8 & 0,0 & 2,4 \\
\hline Centro & 0,4 & 9,0 & 7,9 & 17,3 & 16,1 & 8,3 & 1,1 & 25,5 \\
\hline Este & 0,0 & 0,1 & 1,8 & 2,0 & 1,6 & 1,9 & 0,1 & 3,6 \\
\hline No indentificados & 0,6 & 1,7 & 5,9 & 8,2 & 1,9 & 1,8 & 0,0 & 3,7 \\
\hline
\end{tabular}




\begin{tabular}{|l|l|l|l|l|l|l|l|l|}
\hline TOTAL & 10,4 & 26,8 & 62,9 & 100,0 & 43,7 & 33,4 & 22,9 & 100,0 \\
\hline Fuentes : ACM 14.223, 14.193, 14.204 y 16.922
\end{tabular}

Las cuatro primeras columnas de la tabla 8 ponen en evidencia que aquellos mozos relacionados con las labores agrarias de mantenimiento de los cultivos y el ganado en su mayor parte procedían de las villas de Binissalem o Lloseta, muy próximas al predio, o bien de las villas vecinas que distaban de entre 1 y 6 kilómetros del predio (la aldea de Mancor, en Selva, y Alaró). Del resto de las villas de la sierra eran pocos los mozos que se contrataban en este predio. Sin embargo, las villas del centro de la isla, y en particular una de ellas, Santa Margalida, proporcionaban un número nada despreciable de los mozos que se contrataban como labradores en los meses de invierno, o como mozos para todo el año. Esta movilidad entre el predio y esta villa del centro estaba posiblemente muy relacionada con los centros en donde se reclutaban algunos de los operarios que trabajaban en la cosecha de la aceituna, como veremos, y sobre todo las cogedoras de aceituna, que en una muy elevada proporción procedían de las villas de Santa Margalida, Sa Pobla y Llubí (Jover, 2015).

Las columnas que agrupan los mozos contratados para la cosecha y fabricación del aceite refuerzan esta hipótesis y plantean algunas cuestiones importantes sobre las relaciones entre el origen de los trabajadores y una solución para los costes de supervisión de la fuerza de trabajo. Los mozos que trabajaban en la fabricación del aceite, y muy especialmente los maestros, procedían de Binissalem (6\% respecto del total) y de las villas limítrofes (16,9 \%), básicamente de Selva y Alaró, y de Santa Margalida (16\%). El grueso de los trajineros de sacos, generalmente muchachos o niños, procedían de la parroquia de Binissalem (17\%) y del centro de la isla (8,3 \%), prácticamente en su totalidad de la villa de Santa Margalida. Mientras que la mayor parte de los mayorales de mujeres, aquellos hombres contratados para dirigir y mantener el ritmo de los tajos de cogedoras, procedían de las villas de Alaró y en menor medida de Selva (21,6 \%). Parece, por una parte, que había una estrecha relación entre la procedencia de la movilización del trabajo de las cogedoras y parte del trabajo contratado para la fabricación de aceite (mozos de almazara). Ello quizás procuraba, a las muchachas y mujeres que acudían al predio desde su villa, una cierta protección frente a posibles conflictos al tener cerca el apoyo de vecinos y familiares (padres o hermanos). Sin embargo, para la supervisión de los tajos de cogedoras (mayorales de mujeres) se confiaba en hombres de las villas próximas, los cuales podían ejercer una supervisión no mediatizada por relaciones de vecindad o parentesco.

Esta geografía de los mozos plantea diversas cuestiones. Por una parte, parece que los consejos que proponía el campesino ilustrado Montserrat Fontanet en su tratado no eran seguidos plenamente en este predio. Los terratenientes, en s'Estorell y en otros predios de la hacienda, reclutaban cerca del $70 \%$ de sus mozos en las villas cercanas. Sin embargo, para algunas labores se precisaban mozos de lejos, especialmente cuando se producía la punta de demanda de trabajo durante la cosecha de las aceitunas y la elaboración de aceite. En esos meses, entre octubre y febrero, se hacía necesario recurrir al contrato de mozos y trajineros de sacos para las almazaras que procedían del centro de la isla, de las mismas villas en las que se reclutaban las muchachas y mujeres para la recogida de la aceituna. Esa estrecha relación entre el predio y las villas del centro de la isla, donde se contrataban los mozos para la cosecha de la aceituna, permitía contratar o prolongar contratos para que algunos de esos mozos se enrolaran después como mozos permanentes y labradores del predio. Quizás ello era debido a que, en esos meses en que se labraban los barbechos y los olivares, la oferta de mano de obra local era escasa, pues en una zona como Binissalem y Alaró, las policulturales explotaciones campesinas debían atender a la vendimia (octubre), a entrecavar los cereales, y cavar los pies de los olivos y algarrobos (Grau \& Tello, 1985). La concentración del reclutamiento de los mozos en la villa de Santa Margalida estuvo relacionada con el poder económico, territorial y jurisdiccional que el conde tenía sobre esa villa (Le Senne, 1981; Montaner \& Le Senne, 1977/8). El Conde de Formiguera era el principal señor jurisdiccional y mayor terrateniente de esa parroquia. Por último, la isla imponía ciertas restricciones a los movimientos migratorios extraregionales que caracterizaban las migraciones definitivas o estacionales entre las regiones españolas (Eiras Roel \& Rey Castelao, 1994; Dubert, 2005). El Mar Mediterráneo y los costes del transporte e información constituían barreras a la movilidad laboral, aunque no insalvables. El regular tráfico comercial entre la isla y las regiones vecinas (Serra, Deyá \& Bernat, 
2003; Vaquer Bennasar, 2003); la repoblación del reino de Valencia por parte de mallorquines, muchos de los cuales salieron de la villa de Santa Margalida (Monjo \& Mas, 2005); y la intensa actividad militar de la época de la que participó la isla, mediante levas y el alojamiento de soldados en la isla (Casanova, 2004, pp. 43-82), constituyeron algunos de los factores que propiciaron la movilidad voluntaria o forzosa de las poblaciones de la isla y la cuenca mediterránea en la época. Las cuentas ofrecen dos ejemplos de esa movilidad extraregional. En pocos casos se detectan mozos procedentes de lugares fuera de la isla. En los años 1658-59, 1661-62 y 1673-74, fueron contratados mozos (y jornaleros) procedentes de Menorca, aunque su estancia en el predio fue muy breve: en el primer año un trimestre, y en los otros dos cerca de medio año. En los asientos de 1650 se registra una referencia a la contratación de un mozo llamado "Bielot soldat", aunque no se recoge ni el apellido ni la procedencia.

\section{Conclusión}

Durante la segunda mitad del siglo XVI en la isla se habían producido cambios radicales en las relaciones sociales agrarias. Por una parte, la consolidación de la gran explotación y la creciente especialización agraria de los predios del centro de la isla en el cultivo de los cereales, y los de las sierras en el olivar. Por otra, y consecuencia de la anterior, se habían desarrollado unos amplios mercados de trabajo asalariado a partir del campesinado desposeído y con escaso acceso a la tierra (Bisson, 1977; Moll \& Suau, 1979; Montaner \& Morey, 1989). Esta oferta de trabajo asalariado substituiría progresivamente la mano de obra esclava utilizada desde la conquista en los grandes predios de la isla (Jover, Mas \& Soto, 2002; Mas, 2011). Los rasgos básicos de esos mercados han comenzado a ser estudiados recientemente (Jover, 2012). Por un lado se caracterizaban por su segmentación y por el desarrollo temprano de un mercado de trabajo jornalero. De hecho, este mercado aportaba el $60 \%$ de la mano de obra de los predios. En él los terratenientes reclutaban la mano de obra para recogida de las cosechas (siega, recogida de las aceitunas, vendimia) y para las labores de mantenimiento del olivar y los cereales. El otro rasgo destacado de la emergencia de este mercado fue la creciente participación de las mujeres. A mediados del siglo XVII éstas representaban en los predios de cereal el $80 \%$ de la mano de obra jornalera contratada, un rasgo que se mantendría en los siglos XVIII y XIX (Jover \& Pons, 2012; Jover, 2013; Tello, 1983). En el olivar la proporción era algo inferior, la mano de obra femenina e infantil representaba cerca del $70 \%$ del total de jornales contratados, y en su mayor parte se contrataba para la recogida de la aceituna, mientras los trabajos de mantenimiento del olivo eran asumidos por hombres (Albertí \& Morey, 1986; Escartín, 2001; Grau \& Tello, 1985;; Jover, 2015).

El otro gran mercado de trabajo estaba formado por los mozos. Sus orígenes pueden rastrearse en los mozos que vigilaban los equipos de esclavos o se contrataban por meses en los predios para realizar algunas labores (Montaner \& Le Senne, 1981). Como han mostrado recientes estudios, este segmento del mercado de trabajo se desarrolló en la primera mitad del siglo XVII, siendo un mercado marcadamente masculino (Jover, 2012). Los mozos del predio s'Estorell constituían una parte importante de la fuerza laboral de los predios olivareros, cerca del $40 \%$ del gasto y del trabajo empleado en el predio. Unas proporciones muy semejantes a las encontradas en predios cerealistas de los siglos XVII-XIX (Albertí \& Morey, 1986; Jover \& Pons, 2012; Jover, 2013a; Molina, 2003).

Sin embargo, a mediados del siglo XVII los mozos de este predio no constituían una categoría tan homogénea como la descrita en los predios cerealistas, es decir, integrada en su mayor parte por mozos contratados para todo el año agrícola. Por una parte, en este predio olivarero los mozos constituían un conjunto de tipologías diversas, la mayor parte de las cuales respondían a una contratación con un marcado carácter estacional: contratados para labrar, fabricar el aceite, segar carrizo, etc. El grupo que podríamos describir como mozos permanentes (llamados missatges en la isla) solamente representaban poco más de un tercio del total de mozos contratados en el predio s’Estorell. Este segmento es el que quizás representaba el perfil sociodemográfico más cercano al modelo descrito para los criados rurales jóvenes de algunas regiones atlánticas y mediterráneas.

La explicación del predominio de estas modalidades de contratación temporales, estrechamente vinculadas a 
labores agrarias estacionales (labrar, segar carrizo, manejo de la almazara, etc.), podría relacionarse con el alza de los salarios reales en las décadas centrales del siglo XVII (Jover \& Pons, 2012) y el carácter extensivo del manejo del olivar a mediados del siglo XVII (Bibiloni, 1995; Bisson, 1977). Por otra parte, la información contenida en los libros de cuentas sugiere que, para ejecutar las labores imprescindibles en el manejo del olivar (labrar, cosecha aceitunas y fabricación de aceite), se optaba por la mano de obra experimentada y adulta, evitando así los elevados costes de aprendizaje que supondría la contratación de niños. La contratación de niños y jóvenes se reservaba para unas pocas tareas: trajinero de sacos y algunos mozos de apoyo, sobre los que la documentación y la estructura salarial sugieren un recorrido vital más largo.

El ejemplo estudiado sugiere la presencia de dos modelos sociolaborales diferentes entre los mozos. El primero estaba integrado por un elevado porcentaje de mozos que se contrataban con carácter estacional y no repetían el contrato a lo largo de su vida en ese predio. El segundo, por un reducido grupo de mozos, que tenían una mayor permanencia en el predio, y se contrataban para todo el año y durante largos períodos de tiempo. Para definir de forma más precisa los perfiles sociodemográficos de ambas categorías socioprofesionales será preciso estudiar sus orígenes sociales, la dotación de factores (tierra y capital) que poseían y las estructuras de producción familiar (herencia y matrimonio) de los individuos contratados como mozos.

\section{Bibliografía}

Albertí, A., y Morey, A. (1986). El funcionament d'una possessió mallorquina en el primer terç del segle XIX: Son Vivot del Puig d'Inca. Randa, 20, 5-45.

Antoine, A. (2000). Entre macro et micro. Les comptabilités agrícoles du XVIIIe siècle. Histoire et Mesure, $X V(3 / 4), 247-270$.

Bibiloni, A. (1995). El comerç exterior de Mallorca. Homes, mercats i productes d'intercanvi (1650-1720). Palma de Mallorca: El Tall.

Bisson, J. (1977). La Terre et l'homme aux Illes Baléares. Ais-de-Provença: Edisud.

Casanova, U. de (2004). Aproximación a la historia mallorquina del siglo XVII: política financiera y crisis de subsistencia. Salamanca: Amarú Ediciones.

Dribe, M., y Lundh, Ch. (2005). People on the move: determinants of servant migration in nineteenth century Sweden. Continuity and Change, 20(1), 53-91.

Dubert, I. (2005). Criados, estructura económica y social y mercado de trabajo en la Galicia rural a finales del Antiguo Régimen. Historia agraria: Revista de agricultura e historia rural, 35, 9-26.

Eiras Roel, A., y Rey Castelao, O. R. (1994). Migraciones internas y medium-distance en la Península Ibérica, 1500-1900. Santiago de Compostela: Xunta de Galicia.

Escartín, J. M. (2001). El “Què fer ocult”: el mercat de treball de la dona en la Mallorca contemporània (18701940). Palma de Mallorca: Menjavents.

Florencio Puntas, A., y López Martínez, A. L. (2000a). El trabajo asalariado en la agricultura de la Baja Andalucía. Siglos XVIII y XIX. Historia Agraria, 21, 99-126.

Florencio Puntas, A.; y López Martínez, A. L. (2000b). El mercado de trabajo en la Andalucía latifundista del Antiguo Régimen: ¿intervencionismo o contratación? Historia Agraria, 30, 63-85.

García González, F. (1998). Labradores, jornaleros y sirvientes en la Sierra. Organización doméstica y ciclo de vida (Alcaraz, 1753-1787). En F. García González (Ed.), Tierra y Familia en la España Meridional, siglos XIIIXIX. Formas de organización doméstica y reproducción social (pp. 155-192). Murcia: Universidad de MurciaEditum. 
Garrabou, R., y E. Saguer, E. (1996). Capitalisme agraire sans proletarisation. Les salariés agricoles en Catalogne (XIXe-XXe siècles). En R. Hubscher, y J. C. Farcy (Dirs.), La Moisson des Autres. Les salariés agrícoles auX XIXe et XXe siècles (pp. 57-75). París: Creaphis.

Grau, E., y Tello, E. (1985). Anàlisi de la producció agrària mallorquina en els seus dos aspectes fonamentals: l'oli i els cereals. Randa, 18, 45-91.

Hajnal, J. (1965). European marriage in perspective. En D. V. Glass, y D. E. C. Eversley (Eds.), Population in History (pp. 101-143). Chicago: Aldline.

Jover, G. (2015). Salarios y movilización del trabajo femenino en el olivar: Mallorca, 1650-1720. En T.M. Ortega López (Ed.), Jornaleras, Campesinas y Agricultoras. La Historia Agraria desde una perspectiva de género (pp.43-64.). Zaragoza: Monografías de Historia Rural de la SEHA/Universitarias de Zaragoza.

Jover, G., y Pons, J. (2013). Notes sobre resistència pagesa i paisatges agraris en els dominis de Lloseta-Aiamans i l'alqueria s’Estorell, 1428-1532. Estudis d'Història Agrària, 25, 125-160.

Jover, G. (2012). Tres notes sobre la demanda de treball assalariat a les possessions mallorquines durant el segle XVI. En A. Morey y G. Jover (eds.), Les Possessions mallorquines. Passat i present (pp. 209-231). Palma de Mallorca: Edicions Documenta- Institut d’Estudis Baleàrics.

Jover, G. (2013). La difusión del trabajo asalariado infantil en la agricultura mallorquina: una aproximación a partir de los libros de cuentas de los predios oleícolas, 1700-1850. En J.C. Borrás. (Ed.), El Trabajo infantil en España, 1700-1950 (pp. 27-62.). Barcelona: Universitat de Barcelona/Icaria.

Jover, G., Mas, A. I. y Soto, R. (2002). Feus, reserva senyorial i esclavitud. Mallorca a la segona meitat del segle XIV. En Mir, C. y Vicedo, E. (eds.),_Control social i quotidianitat. Terceres jornades sobre sistemes agraris, organització social i poder local als països catalans (pp. 141-180). Lleida: Institut d’Estudis Ilerdencs.

Jover, G., y Pons, J. (2012). Possessions, renda de la terra i treball assalariat. L’illa de Mallorca, 1400-1660. Girona: Documenta Universitària-Biblioteca d’Història Rural.

Juan Vidal, J. (1989). El cens de Floridablanca a les Illes Balears, 1786-1787. Palma de Mallorca: Font Editor.

Juncosa, M. D. \& C. Martínez (1979). Art de conró compost per Montserrat Fontanet del lloc de Llorito, ólim conductor de son Juan Arnau, y de la Porrasa; mayoral de Masanella, de Lloseta y de son Sanct Juan, segons lo estil de Mallorca, 1747. Estudis d'Història Agraria, 3, 165-96.

Kussmaul, A. (1981). Servants in husbandry in early modern England. Cambridge: Cambridge University Press.

Laslett, P. (1983). Family and household as work and kin group: areas of traditional Europe compared. En R. Wall, y P. Laslett (Eds.), Family Forms in Historic Europe (pp. 513-563.). Cambridge: University Press.

Le Senne, A. (1981). Canamunts i canavalls. Palma de Mallorca: Editorial Moll.

Loder, J., y Moll, I. (1996). Las ocupaciones agrarias en la sociedad rural. En J. L. Balboa López, y L. Fernández Prieto (Coords.), La sociedad rural en la España contemporánea: mercado y patrimonio (pp. 33-62). A Coruña: Ediciones del Castro.

López Estudillo A. (2006). Los mercados de trabajo desde una perspectiva histórica: El trabajo asalariado agrario en la Andalucía Bética (la provincia de Córdoba). Revista Española de Estudios Agrosociales y Pesqueros, 211, 63-120.

Mas Forner, A. (2011). La incidencia del mercado de esclavos en la estructura productiva de Mallorca (aprox. 1300 -1450). En F. P. Guillén y S. Trabelsi (eds.), Les esclavages en Méditerranée Espaces et dynamiques économiques (pp. 77-100). Madrid: Collection de la Casa de Velázquez. 
Molina de Dios, R. (2003). Treball intensiu, treballadors polivalents (Treball, salaris i cost de la vida, Mallorca 1860-1936). Palma de Mallorca: Govern de les Illes Balears.

Moll, I. (1987). La estructura familiar del campesinado de Mallorca, 1824-1827. En D.D.A.A., La familia en la España mediterránea (siglos XV-XIX) (pp. 212-257). Barcelona: Editorial Crítica.

Moll, I., y Suau, J. (1979). Senyors i pagesos a Mallorca (1718-1860/70). Estudis d'Història Agrària, 2 , 95-191.

Monjo Mascaró, J. L., y Mas Forners, A. (2004). Tot hom se'n va a la poblatió de Valèntia. L'emigració mallorquina al regne de València en els segle XVII. Butlletí de la Societat Catalana d'Estudis Històrics,15, 89112.

Montaner, P. de, y Morey, A. (1989). Notas para el estudio de la Mano mayor mallorquina durante los siglos XVI y XVII. Estudis Baleàrics, 34, 71-89.

Montaner, P. de, y Le Senne, A. I. (1981). Explotació d'una possessió mallorquina durant la primera meitat del segle XVI: Son Sureda. Recerques, 11, 107-124.

Montaner, P. de y Le Senne, A. (1977/8). Aproximación al estudio de la clase noble en Mallorca: el patrimonio de los Formiguera. Cuadernos de Geografía, 34, 55-85.

Montaner, P. de y Le Senne, A. (1981). Explotació d'una possessió mallorquina durant la primera meitat del segle XVI: Son Sureda. Recerques, 11, 107-124.

Roca Fabregat, P. (2005). ¿Quién trabajaba las masías? Criados y criadas en la agricultura catalana (1670-1870). Historia agraria, 35, 49-92.

Saguer, E., y Colls, J. (2004). Mossos i criats. Una radiografia del treball assalariat als masos (Girona, 1946). Estudis d'Història Agrària, 17, 813-828.

Sarasua García, C. (2005). “Presentación” al Estudio monográfico: Criados y mozos en la organización histórica del trabajo. Historia agraria, 35, 3-8.

Sarti, R. (2007). Criados, servi, domestiques, gesinde, servant: for a comparative history of domestic service in Europe (16th-19th centuries). Obradoiro de Historia Moderna, 16, 9-39.

Serra Barceló, J., Deyà, M., y Bernat Roca, M. (2003). D'estranya nació: artesanos extranjeros en el Reino de Mallorca (ss. XVI-XVIII). En M. B. Villar García, y P. Pezzi Cristóbal (Dirs.), Los extranjeros en la España moderna: actas del I Coloquio Internacional, celebrado en Málaga del 28 al 30 de noviembre de 2002 (pp. 187201), 1. Málaga: Ministerio de Ciencia e innovación.

Simon Garcia, M. del Mar (2009). Juventud: familia y Trabajo. Jorquera en el siglo XVII. En Gonzalo Aizpuru, P. (Coord.), Familias y relaciones diferenciales: Género y Edad (pp. 127-148). Murcia: Universidad de MurciaEditum.

Snell, K. D. M. (1985). Annals of the labouring poor: social change and agrarian England, 1660-1900. Cambridge: Cambridge University Press.

Tello, E. (1983). La producció cerealícola a les petites explotacions pageses des Pla de Mallorca (1850-51). Estudis d'Història Agrària, 4, 167-194

Vaquer Bennassar, O. (2003). Inmigrantes extranjeros en Mallorca, 1448-1589. En M. B. Villar García, y P. Pezzi Cristóbal (Dirs.), Los extranjeros en la España moderna: actas del I Coloquio Internacional, celebrado en Málaga del 28 al 30 de noviembre de 2002 (pp. 657-666), 1. Málaga: Ministerio de Ciencia e innovación.

\section{Notas}


${ }^{\text {i }}$ Los días no trabajados se descontaban escrupulosamente del sueldo mensual, o bien de la liquidación cuando finalizaba el contrato. Por ejemplo el 14 de marzo de 1663 Joan Baptista Rubí, administrador, pasaba cuentas con Miquel Jaume que había permanecido en el predio por un largo período: “contat totes les faltes e festes y trop estat 4 anys 7 mesos y 26 dias an valgut lo que dit a gonyat per son salari 142 l[liures] 13 s[ous] i 4 d[iners]" El mozo reconocía una deuda con el administrador de 7 libras 2 sueldos y 8 dineros, y volvía a contratarse ese mismo día por un sueldo mensual de 50 sueldos ACM, 14.204, f. 69-23v.

ii Así, también lo consideraron los peritos que en 1687 valoraron el predio para ejecutar su partición y venta para el pago de deudas. En esa ocasión se valoró en 50.200 ls, mientras en el catastro de 1688 se valoró en 55.000 (ACM, 14.165, f. 130v-131r)

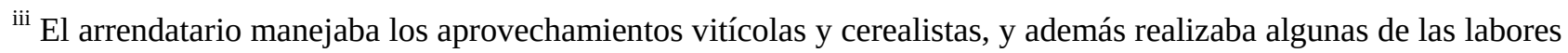
del mantenimiento del olivar como labrar, cavar los pies y podar. El terrateniente pagaba una ayuda al arrendatario por esas labores destinadas al olivar (ACM, 14.223).

${ }^{\text {iv }}$ Aunque en el pleito se resumen las cuentas generales de gastos en ingresos de los años 1652 a 1656, véase ACM, 5.494.

v En el nuevo libro se debían anotar los mozos nuevos a partir de 1675 y los jornales a partir de 1679. Posiblemente este libro, que suponemos se extendía hasta 1686, fue utilizado por los peritos y magistrados que hicieron las valoraciones económicas para sustanciar el pleito de partición del predio en 1686/7.

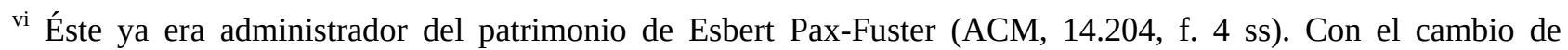
propiedad nuevamente Jaume Antoni Rubí asumió la administración de las nuevas fincas de la casa Formiguera (Archivo del reino de Mallorca [ARM], Protocolos Notariales [PN], S-90, f. 13).

${ }^{\text {vii }}$ Las cuentas de la cosecha del aceite de 1645-46 y otros libros de administración muestran que efectivamente se consumían esos productos en el predio, y que en algunos casos formaban parte del "salario en especies" que se proporcionaba a determinados mozos y jornaleros.

viii Por ejemplo en un contrato conservado del 3 de setiembre de 1603 el administrador "a raó de 1 l [iure] 10 s[sous] cada mes per temps de dos anys y una reserva de un mes cada any an temps de segar” ACM, 14192, s/f.

${ }^{\text {ix }}$ Véanse las anotaciones en los libros de cuentas del período estudiado: ACM 14.223, 14.193, 14.204 y 16.922

${ }^{\text {x }}$ Por ejemplo, fue la hija del mozo Miquel Matgi (1674-1678) la que cobró diversos pagos mensuales a cuenta del salario de su padre, y su mujer fue la que liquidó la cuenta de su marido al terminar el contrato.

${ }^{x i}$ El salario de Joan Barrás, mozo entre 1672 y 1674, fue cobrado en numerosas ocasiones por su hija.

xii Era la mujer de Joan Negrat (1675-1678) quien recogía el salario de su marido. Véase ACM 14.193 f. 50-51v. 